\title{
LOS PÚLPITOS PARA EL CANTO DE LA EPÍSTOLA Y DEL EVANGELIO EN LAS IGLESIAS PARROQUIALES DE JEREZ DE LA FRONTERA (SIGLOS XVI-XVIII)
}

\author{
THE AMBONS FOR THE SONG OF THE EPISTLE \\ AND THE GOSPEL AT THE PARISH CHURCHES IN JEREZ \\ DE LA FRONTERA $\left(16^{\mathrm{TH}}-18^{\mathrm{TH}}\right.$ CENTURIES $)$
}

\author{
Pablo J. Pomar Rodil \\ Universidad de Cádiz. España \\ ORCID: 0000-0002-0918-1739 \\ pablo.pomar@uca.es
}

La funcionalidad de los púlpitos gemelos o ambones, que, ubicados a la entrada del presbiterio, servían para el canto de la epístola y el evangelio durante las misas solemnes celebradas con asistencia de ministros sagrados, ha venido siendo relegada por los trabajos de historia del arte que de estos elementos se han ocupado. El presente artículo trata de clarificar su uso y deslindarlos funcionalmente del púlpito de la predicación. Para ello se analizan, como una suerte de muestreo local de un asunto general, los de las parroquias de una de las poblaciones de mayor vitalidad eclesiástica del antigua archidiócesis de Sevilla, la de Jerez de la Frontera.

Palabras clave: púlpito; ambón; epístola; evangelio; Jerez de la Frontera.

The functionality of the twin pulpits or ambons, which, located at the entrance of the presbytery, served for the singing of the Epistle and the Gospel during the solemn masses celebrated with the assistance of sacred ministers, has been relegated by the works of art history that have been taken care of these elements. This paper tries to clarify their use and functionally demarcate them from the pulpit of preaching. For this purpose, as a kind of local sampling of a general matter, those of the parishes of one of the most vital cities of the former Archdiocese of Seville are analyzed: Jerez de la Frontera.

Keywords: pulpit; ambon; Epistle; Gospel; Jerez de la Frontera. 


\section{EL AMBÓN, USO LITÚRGICO Y EVOLUCIÓN TIPOLÓGICA}

El ambón paleocristiano, inscrito inicialmente en el ámbito de la schola cantorum, tuvo su particular desarrollo evolutivo ligado a la compartimentación de la nave del templo medieval, dando origen a la aparición del lettner en Alemania, el jube en Francia, el conocido leedoiro de Santiago de Compostela o, en Italia, a algunos pontili y tramezzi que llevaban aparejada la función de tribuna para la proclamación de las sagradas escrituras al pueblo durante la misa ${ }^{1}$. Sin embargo, las iglesias de ámbito hispano consolidaron durante la Baja Edad Media, y aún mantuvieron durante el Renacimiento y el Barroco, un modelo tipológico que solía contar, a ambos lados de la grada que da acceso al presbiterio, o avanzando un poco desde esta hacia la nave, con dos púlpitos gemelos destinados durante la misa solemne a una función litúrgica específica: el canto del evangelio, en el que se situaba a la izquierda, y de la epístola, en el del lado derecho².

Remontarse al origen de los ambones es hacerlo cuanto el propio culto cristiano, como pone de manifiesto su pervivencia, o la evidencia arqueológica de su pretérita existencia, en tantas basílicas paleocristianas ${ }^{3}$. Además, conviene detenerse sobre la evolución de estos elementos litúrgicos durante la Edad Media, particularmente en Italia, donde, además de las tipologías divisorias anteriormente señaladas, con frecuencia adoptaron la forma de elevadas tribunas marmóreas que, ubicadas cerca del presbiterio, eran utilizadas durante las misas solemnes ${ }^{4}$. Pero estos ambones habrían dejado de levantarse ya en el siglo XIII y, aunque los existentes continuaron utilizándose, paulatinamente fueron cayendo en desuso, removiéndose y desbaratándose muchos de ellos ${ }^{5}$. Durante el Renacimiento, se dieron casos, singulares pero significativos, de reaparición de estas piezas litúrgicas en el contexto de un revival paleocristiano que habría tratado de reconciliar antigüedad y cristianismo mediante un retorno a las formas arquitectónicas y artísticas de los primeros tiempos de la vida de la Iglesia ${ }^{6}$. Cabe destacar al respecto la pareja de púlpitos de la catedral de San Juvenal de Narni, de 1490, y, muy especialmente, el caso de la basílica de San Lorenzo de Florencia, donde, también a finales del siglo XV, el círculo de intelectuales encabezado por Cósimo de Medici habría jugado un papel determinante en la decisión de erigir los célebres púlpitos gemelos de Donatello, que se ubicaron inicialmente junto a los pilares angulares

${ }^{1}$ Abundante bibliografía al respecto en Carrero Santamaría, 2008: 175-176, notas 6-7.

2 Jungmann, 1951: 533, nota 91.

3 Leclercq, 1907: I, 1330-1347. Heid, 2017: 76-102.

${ }^{4}$ La bibliografía sobre los púlpitos litúrgicos medievales italianos es extensísima. Una sucinta selección de la misma en Stabenow, 2006: 228, nota 2.

${ }^{5}$ Sobre el aprecio y desprecio de los ambones medievales en Italia durante la Edad Moderna véase Milone/Novello, 2006: 112-117.

${ }^{6}$ Lavin, 1959: 38. 
del transepto7. En el ámbito lombardo, las figuras de Pellegrino Tibaldi y San Carlos Borromeo destacan, como autor material y teórico respectivamente, en soluciones de renovado diseño tipológico, como los púlpitos de Santa María la Mayor de Bérgamo y de la catedral de Milán ${ }^{8}$. Borromeo, además, contempló en su célebre Instructionum de 1577 la posibilidad de que en los nuevos templos se continuasen levantando parejas de ambones, uno para cantar la epístola y otro para el evangelio, más suntuoso y elevado este último9. Se ha señalado cómo el cardenal milanés pudo haber encontrado inspiración para esta tipología de ambones en los numerosos ejemplares de progenie paleocristiana que habría conocido en las antiguas basílicas de Roma ${ }^{10}$. Precisamente, durante la intervención que en el cambio de siglos acometería el cardenal César Baronio en dos de estas, concretamente en las de San Cesáreo en la Vía Apia y de San Nereo y Aquileo, se recrearon ámbitos presbiteriales de neta inspiración paleocristiana, si bien bajo un modelo evolucionado que incluiría en ambas basílicas sendas parejas de simplificados púlpitos gemelos ${ }^{11}$.

Finalmente, la paulatina desaparición de cualquier estructura arquitectónica levantada específicamente para esta ceremonia sería la tónica dominante durante la Edad Moderna, cuando se había consolidado, como un nuevo signo de reverencia hacia el evangelio, la praxis de que fuese el subdiácono quien sostuviese el libro, lo que convertiría en innecesaria a tal efecto cualquier pieza arquitectónica o mobiliaria ${ }^{12}$. A la postre, fue este modo de desarrollar la ceremonia el que quedó recogido en el Ritus Servandus in Celebratione Missae, conjunto de rúbricas que anteceden al nuevo misal que el Concilio de Trento había encargado al

7 Stabenow, 2006: 256. Lavin, 1994: 6-7.

${ }^{8}$ Stabenow: 2007: 227-234, nota 25.

9 "Habenda est quoque in ecclesiis insignioribus ac praesertim in basilicis cathedralibus ratio ambonum; quos et magnos, et ornate confectos, et tabulis marmoreis ornatos extitisse, in basilicis Romanis perspici licet, et alibi etiam aeneis, caelato sacrarum imaginum opere expressis. De duobus ambonibus. Item duo pro ecclesiarum magnitudine constitui possunt: unus altius extructus, de quo evangelium, alter de quo epistola lectiove sacrae scripturae in maioribus solemnitatibus pronuncietur. Hicque paulo depressior sit quam ille unde evangelium legitur. De uno ambone. Unus etiam tantum ambo, ut in multis ecclesiis cernitur, esse potest, qui et evangelii et epistolae simul lectioni usui sit: ita tamen ut in eo locus, unde evangelium recitatur, aliquanto eminentior sit; pars vero, unde epistola, aliquo gradu inferior sit. Infima item pars sub ambone vel alius locus inferior detur, ubi cantoribus clericisve spatium sit, unde in solemnitatibus certisque diebus de antiquo Ecclesiae more stata cantica, praesertim inter epistolam et evangelium, canant. In ambone, ubi potest, constituantur duo graduum ordines: unus, quo fit ascensus ad orientem versus; alter occidentem spectans, quo fiat descensus". Borromeo, 1859: 116-117.

${ }_{10}$ Stabenow, 2007: 253-258.

${ }^{11}$ Herz, 1988: 599 y 602-603. Lavin, 1994: 32.

12 Jungmann, 1951: 532-533. 
papa y que fue promulgado en 1570 por San Pío $\mathrm{V}^{13}$. Este mismo corpus de rúbricas establecía que el evangelio se cantase "versus populum", pero añadiendo, inmediatamente a continuación, la locución "contra altare", lo que desconcertó a muchos rubricistas por la aparente contradicción que entraña. Así, en 1589, el célebre computista toledano Pedro Ruiz de Alcoholado haría notar con perspicacia que "en el lugar y modo de decir el Evangelio han dudado muchos y es por estar en la rúbrica algo confuso, que dize el diácono va con el subdiácono a su siniestra al lugar del evangelio, contra el altar hacia el pueblo: la dificultad está en el contra y versus, que parece significar lo mesmo" 14 . Es posible que esta paradoja encuentre explicación en haberse seguido en la confección de las rúbricas del nuevo misal piano los usos del Missale secundum consuetudinem Romanae Curiae, que bien pudieron haber respondido a la particular topografía de algunas de las antiguas basílicas romanas, como la de San Pedro del Vaticano, cuyo ábside, al mirar a Occidente, contaba con un altar exento donde el papa, para celebrar orientado, debía hacerlo de cara a los fieles ${ }^{15}$.

\section{LOS PÚLPITOS GEMELOS: PARTICULARIDAD HISPANA Y LITURGIA ROMANA}

Los liturgistas españoles que trataron de encontrar explicación a la discrepancia flagrante entre rúbricas defendieron la proclamación del evangelio cara al pueblo. Por ejemplo, el liturgista Juan Gascón, visitador general de la diócesis de Huesca, sostuvo que, si bien el subdiácono debía cantar la epístola cara al altar, con el libro en un atril colocado en el plano del presbiterio, el evangelio había de cantarse cara al pueblo, ya fuese desde el púlpito o con el evangeliario sostenido por el subdiácono ${ }^{16}$. Cuatro años más tarde, Ruiz de Alcoholado enten-

${ }^{13}$ Respecto a la epístola, el Ritus Servandus señala que "In Missa solemni subdiaconus circa finem ultimæ orationis accipit ambabus manibus librum Epistolarum, deferens illum supra pectus, et, facta altari genuflexione in medio, vadit ad partem Epistolæ contra altare, et cantat Epistolam", y, en cuanto al modo de cantar el evangelio, "diaconus [...] vadit cum subdiacono a sinistris ad locum Evangelii contra altare versus populum, ubi, subdiacono librum tenente". Ritus Servandus in Celebratione Missae (VI, 4-5).

${ }_{14}$ Ruiz Alcoholado, 1589: 36v.

15 Lang, 2007: 73-98.

${ }^{16}$ Sobre el modo de cantar la epístola, Gascón dará las siguientes instrucciones: "El subdiácono [...] baxa a la parte de la Epistola, debaxo las gradas, donde hay un facistol, pone el Missal en él y buelto al Altar, canta la Epístola". Y, en cuanto al modo de proceder con el evangelio, estas otras: "Recibida la bendición va el diácono al púlpito [...]. Dize allí el evangelio con la ceremonia acostumbrada". Pero también prevé otra posibilidad: "Si el Diácono no quisiere yr a dezir el Evangelio al púlpito, ha de hazer desta manera: que hauiendo recebido la bendición del celebrante, ha de yr [...] al lugar donde se canta el Evangelio, que es el lado derecho del Altar debaxo de sus gradas, y allí de cara al pueblo 
dió la confusa rúbrica romana en un sentido semejante al afirmar que "el decir la epístola el subdiácono ha de ser al lado de la epístola hazia el altar, y débese tener el libro el subdiácono. [...] Dezimos que sin duda quieren decir estas palabras que venga el diácono de tomar la bendición y que se ponga en el lugar en se suele decir el evangelio, y puesto allí (no en el altar sino contra o en frente de aquel lugar del altar en que se suele decir el evangelio) se vuelva al pueblo para decir Dominus vobiscum, y todo el evangelio, de manera que ha de tener las espaldas vueltas al lado del altar, adonde se acostumbra a decir el evangelio en missas privadas. Y esto no solo de aquí pero de otras rúbricas consta: y que versus populum quiere dexir hacia el pueblo no ay principiante de grammatica que no lo entienda" 17 .

Sin embargo, estas no serían las interpretaciones predominantes fuera de España, de modo que, con posterioridad, en 1600, el Ceremonial de los Obispos proclamado por Clemente VIII recogería un distinto desarrollo de la rúbrica, según la cual el subdiácono habría de sostener el libro situándose en el presbiterio de espaldas al muro del lado del evangelio y, por tanto, con el altar a su izquierda y la nave del templo a su derecha ${ }^{18}$. Frente a él se situaba el diácono, que proclama el evangelio mirando hacia el muro norte ${ }^{19}$. Se trataba de un modo de desarrollar la ceremonia ya conocida en la Edad Media y que Bernoldo de Costanza (†1100) había criticado como "certissime contra ordinem et inhonesta" 20 .

También se constata, particularmente en España, la permanencia durante toda la Edad Moderna de púlpitos provistos de atriles, así en catedrales como colegiatas, parroquias o en cualquier otra iglesia que pudiese prever el desarrollo habitual de un culto solemne, lo que pone de manifiesto una cierta prolongación de la praxis antigua que preveía este mobiliario litúrgico para el canto de la epístola, los evangelios, la secuencia, el gradual, el aleluya y el tracto ${ }^{21}$. Para explicar esta continuidad conviene recordar que la constitución apostólica Quo Primum Tempore, mediante la cual, el 14 de julio de 1570, San Pío V promulgó el nuevo Missale Romanum, permitía a las iglesias locales el mantenimiento de las costumbres litúrgicas propias que tuviesen una antigüedad ininterrumpida de al

(teniéndole el Missal el Subdiácono, que está entre los dos monazillos de los cirios encendidos) ha de cantar el Evangelio de la manera que diximos que lo hauia de cantar en el púlpito". Gascón, 1585: 143-146.

17 Ruiz Alcoholado, 1589: 36v.

18 "Cum pervenerint ad locum, ubi solet Evangelium decantari, Subdiaconus medius inter dictos ceroferarios tenet librum Evangeliorum apertum ante pectus, vertens renes non quidem altari, sed versus ipsam partem dexteram, quae pro Aquilone figuratur". Caeremoniale Episcoporum, 1600: $74 \mathrm{v}$.

${ }^{19}$ Righetti, 1956: II, 232, nota 98.

20 Jungmann, 1951: 188 y 526-527.

${ }^{21}$ Ya nos ocupamos sucintamente de la permanencia en España de estos púlpitos gemelos en Pomar Rodil, 2002: 365-371. 
menos doscientos años ${ }^{22}$. Todo parece indicar que el uso de estos púlpitos para la epístola y el evangelio pudiera haber sido ya entonces más que bicentenario en España. Sin embargo, bien sea porque se contase con pocos instrumentos con los que poderlo acreditar, o más bien por el notorio celo litúrgico del rey Felipe II, este se empeñó en obtener del papa una bula que librase al clero español de cualquier escrúpulo respecto del mantenimiento de ese y otros usos litúrgicos hispanos que entraban en contradicción con las rúbricas del nuevo misal ${ }^{23}$. En efecto, el breve Ad hoc Nos Deus unxit, de 16 de noviembre de 1570, permitía que en las iglesias de España el diácono proclamase el evangelio desde un atril preparado para ello, algo que, por extensión, se aplicó con la epístola ${ }^{24}$. El breve pontificio sirvió para que se perpetuasen estos púlpitos, ya enraizados en la tradición litúrgica hispana a través de extraordinarios ejemplares como los catedralicios de Toledo o Sevilla y de ello se ocuparon los liturgistas del siglo XVI tratando el alcance del privilegio. Así, la posibilidad de utilización del púlpito es contemplada por el oscense Juan Gascón a quien ya citamos anteriormente ${ }^{25}$. Y también por Ruiz Alcoholado, quien advirtió de que por el breve de marras "está dispensado sobre tener el libro el subdiácono, no habiendo púlpito en que se diga el evangelio, y no de otra manera y presupone que los púlpitos están hazia el pueblo, que en ninguna parte se ha de dezir el Evangelio cantando hazia el altar, sino hazia el pueblo en missa con diáconos" ${ }^{26}$.

Aunque el testimonio de Alcoholado se centre en justificar la licitud del canto del evangelio en el púlpito cara al pueblo, también parece desprenderse de sus palabras una implícita referencia al gemelo de la epístola. Lo cierto es que en el rito romano, incluso en las misas solemnes, se conservaba la mayor simplicidad en la presentación de la epístola y, contrariamente a cuanto sucede con la proclamación del evangelio, no se hacía ninguna invitación al pueblo, ni bendición alguna al lector, tampoco oración para pedir la purificación de los pecados o para anunciar dignamente la palabra divina, ni tampoco procesión. Según Jungmann, el enriquecimiento progresivo de las ceremonias relativas a la proclamación del evangelio, al tiempo que premeditadamente se mantenía la primitiva sencillez en las de la epístola, sirvieron para resaltar la categoría del primero ${ }^{27}$. Sin embargo, el hecho de que, mediante el breve de privilegios litúrgicos concedidos a España por San Pío V, el evangeliario pudiera ser cantado desde un atril propició que al mismo tiempo se mantuviese la práctica en el caso de la epístola, toda vez que de

\footnotetext{
22 Jungmann, 1951: 192.

23 Sobre el interés y conocimiento de Felipe II de las ceremonias litúrgicas, se conservan numerosas noticias, véase Pomar Rodil, 2015: 95-97.

24 Pomar Rodil, 2015: 95-97.

25 Gascón, 1585: 143-144.

26 Ruiz Alcoholado, 1589: 36v.

27 Jungmann, 1951: 535.
} 
haber seguido fielmente lo previsto por las rúbricas del misal habría quedado en apariencia cargado de mayores signos de reverencia que hacia el evangelio, dado que el Ritus Servandus prevé que sea el propio subdiácono quien sostenga el epistolario ${ }^{28}$. En cualquier caso, tanto para la epístola como para el evangelio, en el anteriormente citado Ceremonial de los Obispos aparece ya recogida, como alternativa a la praxis romana previamente descrita, la posibilidad de uso de los púlpitos con carácter universal ${ }^{29}$.

\section{LOS PÚLPITOS GEMELOS EN LAS PARROQUIAS DE JEREZ DE LA FRONTERA}

En el ámbito de la archidiócesis de Sevilla supusieron un primer prototipo a emular los púlpitos gemelos de su catedral, que debieron de perecer, o quedar seriamente dañados, tras la caída del cimborrio en 1511. Eran de jaspe verde de Setúbal -aún se conservan los fustes de sus columnillas de apoyo integrados en la portada lateral de la capilla de la Virgen de la Antigua- y habían sido diseñados en 1504, conjuntamente con las gradas del presbiterio, por el maestro Alonso Rodríguez. También de referencia fueron los extraordinarios ejemplares de bronce que los sustituyeron entre 1527 y 1532 (Figura 1), piezas que los capitulares encargaron a Francisco de Salamanca con la pretensión de que fuesen "los más ricos e decentes que se pudieren" ${ }^{\prime 0}$. Afortunadamente estos sí se han conservado, sin embargo, hemos de lamentar la completa desaparición de otros muchos, y entre ellos también algunos de los que existieron en las iglesias parroquiales de Jerez de la Frontera, de los que nos ocupamos a continuación.

A pesar de los pocos datos conocidos de la antigua colegiata medieval de San Salvador, sabemos por don Gonzalo de Mier y Barreda, visitador del arzobispado hispalense, que los púlpitos gemelos para la epístola y el evangelio con que contaba el templo en 1673 estaban realizados en piedra y los suponemos

28 Righetti, 1956: II, 231.

${ }^{29}$ Respecto al canto de la epístola, tras señalar el modo descrito en la nota 16, "Subdiaconus [...] sibi ipse tenens librum, extra presbyterium a latere sinistro altaris, vel, ubi ita consuetum sit, in ambone, cantat Epistolam alta voce". Y en cuanto al evangelio: "Si vero in Ecclesia fuerint legilia, vel ambones, in illis poterit cantari Evangelium, videlicet, si cantabitur in legili, seu pulpito, Subdiaconus stabit post illum, qui panno aureo, vel serico coloris caeterorum paramentorum coopertus \& ornatus esse debet, amplectens ipsum legile \& manibus hinc inde librum tangens. Quod si cantabitur in ambone lapideo ad quod per gradus ascenditur, prout adhuc in pluribus Ecclesijs, iuxta antiquam consuetudinem, huiusmodi ambones reperiuntur; tunc Subdiaconus assistet, \& ministrabit Diacono opportuna stans a latere eius dextero; videlicet, porrigens thuribulum, \& vertens solia libri Evangeliorum, cum opus erit". Caremoniale Episcoporum, 1600: 73v-74v.

${ }_{30}$ Rodríguez Estévez, 2006: 172. Jiménez Martín, 2006: 90. Gallego de Miguel, 1981: 243-244. 
notablemente elevados dada la posición del presbiterio y hasta un tanto avanzados si nos atenemos a que el tránsito que unía el altar con el púlpito del lado del evangelio llegaba a dar cabida a la sepultura principal de las que en el presbiterio tenía la familia Cabeza de Vaca ${ }^{31}$. En el templo que habría de sustituirlo en el siglo XVIII - actual catedral- se optaría por una solución de forja (Figura 2), de la que se encargaría el maestro Pedro Dorado en 1778 y que acaso pueda rastrearse entre cuanto apreciamos en el material fotográfico que se conserva de la colegiata antes de su desastrosa reforma de los años sesenta del siglo $\mathrm{XX}^{32}$. Los ocho balconcillos de baranda que se divisan en estas imágenes responden ya a las necesidades del modelo de altar cuadrifronte inaugurado en 1907, si bien no podemos descartar que la intervención entonces se hubiese limitado a la reproducción en los lados restantes del frente del siglo XVIII ${ }^{33}$.

También de piedra fueron los de la opulenta parroquia de San Miguel (Figura 3), que el jerónimo e historiador fray Esteban Rallón describió como "muy primorosos, con mucha talla y escultura" 34 . Realizados en piedra de las canteras de Martelilla, sus restos se exponen en el Museo Arqueológico de Jerez ${ }^{35}$. En total se trata de seis piezas del pretil, dos fragmentos de basa y seis hornacinas con esculturas de San Lucas, San Marcos, San Miguel, San Pedro, San Pablo y la Virgen con el Niño. Dada la íntima relación que entre iconografía y función solía darse en estas piezas, cabe pensar que el púlpito del lado del evangelio albergase las dos primeras figuras y quedase completado con las de los otros evangelistas, San Juan y San Mateo. Mientras que el púlpito del lado de la epístola contase con San Pablo, San Pedro y quizá el profeta Isaías y San Judas, cuyas lecciones también sustituyen en ciertas ocasiones del año a las cartas del apóstol de los gentiles ${ }^{36}$. Los relieves de San Miguel y la Virgen centrarían la decoración figurativa de ambos grupos, completando su iconografía con imágenes alusivas al titular del templo y

31 "Dos púlpitos de piedra donde se cantan las epístolas y evangelios". Jiménez López de Eguileta/Pomar Rodil, 2014: 472, 474 y 479.

32 Repetto Betes, 1978: 137.

${ }_{33}$ Mariscal Rodríguez/Pomar Rodil, 2001: 100.

34 "Tiene a los lados dos púlpitos para decir la epístola y el evangelio, y ellos y las gradas son de piedra de martalilla [sic] muy primorosos con mucha talla y escultura". Rallón, 2003: IV, 138.

${ }^{35}$ La azarosa historia de ambos púlpitos incluye su unión para formar brocal del pozo de la parroquia. Su conservación en el museo consta al menos desde 1914. Pescador y Gutiérrez del Valle, 1914: 102.

${ }^{36}$ Se ha planteado recientemente una reconstrucción de ambos púlpitos diferente y, a nuestro entender, sin fundamento, dado que, además de desconocer la finalidad funcional que genera y condiciona su iconografía -hasta el punto de no hacer distingos entre el uso de estos púlpitos y el de la predicación-, analiza esta última con pretensiones iconológicas de matriz apocalíptica que a nuestro entender carecen de cualquier verosimilitud. Aguayo Cobo, 2014: 63-82. 
a la Madre de Dios, a quien estaba dedicada, bajo la advocación del Socorro, el gran altar de la nave de la epístola.

Presentaban estos púlpitos como interés adicional el haberse realizado en el contexto de la obra general del templo, conjuntamente con las gradas originales de su primitivo presbiterio, que habría sido levantado hacia 1550 bajo la dirección de Pedro Fernández de la Zarza, pero con la colaboración probable, en las labores escultóricas, de los entalladores Cristóbal de Voisín y Pedro Daza ${ }^{37}$. No hay certeza de cuándo estos púlpitos fueron retirados ${ }^{38}$. Cabe pensar que, muy probablemente, la sustitución de las gradas del presbiterio en 1789 pudiera haber acarreado la de los púlpitos, que formaban un todo con estas al haberse construido conjuntamente y del mismo material ${ }^{39}$. También es posible, por tanto, que en el mismo proceso de renovación del presbiterio, adoptando el modelo de la colegiata, al tiempo que emulando a la parroquia de Santiago, los viejos púlpitos de piedra hubiesen sido sustituidos por los de balconcillo de forja que, aunque mutilados y despojados de sus pilares sustentantes, aún se conservan (Figura 4). Suponemos que estos han de estar relacionados con los trabajos que en el coro y en la vía sacra corrieron en aquellos años a cargo del herrero Pedro Dorado, a quien quizá quepa atribuirle su creación, que estéticamente habría de conformar un todo ${ }^{40}$.

Púlpitos destacados fueron igualmente los de la parroquia de Santiago, que afortunadamente se conservan, a pesar de las muchas vicisitudes e intervenciones que ha sufrido el templo (Figura 5). Se trata de dos balcones gemelos de forja, con balaustres y cornisa decorada con motivos de progenie clásica, dotados de escalerillas y sostenidos por un pilarete bulboso. Fueron encargados por la fábrica

${ }^{37} \mathrm{La}$ endiablada sucesión de contratos y subcontratos que tienen lugar a mediados del siglo XVI entre los distintos maestros ligados a la fábrica desvela un intrincado modo de adjudicación de obras que complica sobremanera la siempre deseable precisión en cuanto a atribuciones y autorías. Agradecemos a nuestro colega Manuel Romero Bejarano tanto sus sagaces apreciaciones al respecto, como la noticia inédita, que pronto dará a conocer, donde se documenta la presencia de Voisín y Daza en la obra de San Miguel. Romero Bejarano/Romero Medina, 2011: 207. Romero Bejarano, 2014: 359.

${ }^{38}$ La profesora Esperanza de los Ríos propone la fecha de 1788. El asiento documental en el que basa la afirmación, que hemos revisado a conciencia, no lo confirma completamente. Se trata de un inventario de 1785 en el que se señala la existencia del púlpito de hierro en el cuerpo de la iglesia "y dos de piedra en el altar mayor", al cual, en algún momento posterior, se le ha añadido como nota marginal "extinguidos estos". Sin embargo, no hemos encontrado señal alguna de que dicha apostilla fuese introducida en 1788. De los Ríos Martínez, 1996: 149. Archivo Histórico Diocesano de Jerez de la Frontera (AHDJF), San Miguel, sección III, caja 35, doc. 6.2.

39 Aroca Vicenti, 2002: 224. La referencia a 1799 es una mera errata tipográfica, como se deduce de una atenta lectura del párrafo completo, así como de la nota 111 que lo acompaña.

40 Aroca Vicenti, 2005: 336 y 338. 
parroquial a los herreros residentes en Cádiz Roque y Francisco de Caos en $1628^{41}$. Dos años más tarde, un joven Alonso Cano acometió el dorado de ambas piezas, que con ello quedarían concluidas ${ }^{42}$. Sobre el alcance de esta última intervención no cabe duda de que el resultado final es semejante al que aún conserva y que el trabajo de Cano no se extendió a un dorado completo de ambas piezas sino que se limitó a sus relieves decorativos y atriles, como acreditan en el tercer cuarto del siglo XVII los testimonios de fray Esteban Rallón y de don Gonzalo de Mier ${ }^{43}$.

Del resto de púlpitos de las capillas mayores de las parroquias, debido a las profundas transformaciones sufridas por los templos jerezanos durante el último tercio del siglo XIX, solo existen -y no en todos los casos- someros testimonios documentales. Sí quedan fotografías de los de la parroquia de San Lucas (Figura 6), que fueron removidos en la década de $1960^{44}$. Gracias a estas imágenes, a los restos que permanecen in situ y a lo recogido en un inventario parroquial de 1886 sabemos que eran de hierro forjado sobre zócalos de jaspe negro ${ }^{45}$. Fueron realizados en 1729 durante las obras de reforma barroca del templo medieval y vinieron a sustituir a otros precedentes de los que apenas sabemos que en 1635 fueron dorados por el maestro Antonio de Benavente ${ }^{46}$. De los púlpitos gemelos de la iglesia parroquial de San Mateo contamos una vez más con el testimonio de la visita de 1673, donde De Mier los ubicará "incorporados acerca del altar mayor", con lo que quizá quisiese decir avanzados sobre la nave respecto del límite del arco triunfal, añadiendo además que eran nuevos y estaban dorados, deduciéndose de ello que acaso fuesen de forja ${ }^{47}$. También ligeramente volados hacia la nave pudieron ser los que el arzobispo don Jaime de Palafox mandó que, en forma de balcón, se hicieran en San Marcos, parroquia que visitó en diciembre de $1691^{48}$. Consta que en 1695 estaban ya terminados, habiéndose ocupado de su ejecución el maestro herrero Francisco Monge ${ }^{49}$.

${ }^{41}$ De los Ríos Martínez, 1996: 144-145.

42 De los Ríos Martínez, 1996: 144-145.

${ }^{43}$ Fray Esteban Rallón dirá que "los púlpitos de la epístola y el evangelio son de hierro con los botones y hojas dorados. Las barandillas y pasamanos de escaleras son de lo mismo, y de la misma obra". Pocos años más tarde, el visitador De Mier y Barreda describe que "en el altar mayor hay dos epistolarios de hierro de negro y dorados". Rallón, 2003: IV, 140. Archivo General del Arzobispado de Sevilla (AGAS), sección II, Visitas, leg. 1443.

44 Álvarez Luna/Guerrero Vega/Romero Bejarano, 2003: 269.

${ }^{45}$ Un inventario de la parroquia realizado por don José María Arcila Navarro en 1886 describe "dos balaustradas y atrileras de hierro dulce; la escalinata y zócalos son de jaspe negro". AGAS, sección IV, serie 13.

46 Antón Portillo/Jácome González, 2001: 117. Aroca Vicenti, 2002: 196.

47 "Tiene dos púlpitos para leer los evangelios y epístolas incorporados acerca del altar mayor. Están dorados y es fábrica nueva”. AGAS, sección II, Visitas, leg. 1443, s. f.

48 "Que se saque un balcón sobre el parapeto sobre el altar mayor y se hagan púlpitos para cantar la epístola y el evangelio". AGAS, sección II, Visitas, leg. 1339, f. 52r.

49 Sancho de Sopranis, 1936: 5. 
De las parroquias de San Juan de los Caballeros y de San Dionisio no hemos alcanzado a encontrar registro alguno sobre sus púlpitos gemelos para el evangelio y la epístola, con los que sin duda debieron contar y que tuvieron que desaparecer a finales del siglo XIX, durante las reformas acometidas en ambos templos por el arquitecto municipal don José Esteve y López ${ }^{50}$. Por otra parte, el avaro caudal de noticias del que nos hemos servido en el presente trabajo se deseca completamente al tratar de documentar estos elementos de uso cultual en los conventos y monasterios de la ciudad, lo que nos ha impedido conocer las diferencias -quizá- y semejanzas - muy probablemente- que pudiesen haber guardado con los casos parroquiales objeto del presente análisis ${ }^{51}$. Queda para mejor momento también el estudio de las transferencias tipológicas entre estas parejas de púlpitos litúrgicos del presbiterio y el que en la nave servía para la predicación, de cuyo uso ya nos ocupamos in extenso en otra ocasión ${ }^{52}$.

Fecha de recepción: 30 de octubre de 2019

Fecha de aceptación: 13 de abril de 2020

\section{BIBLIOGRAFÍA}

Aguayo Cobo, Antonio (2014): "Los púlpitos de San Miguel en Jerez de la Frontera. Reconstrucción y análisis dentro del programa apocalíptico del templo". En: Boletín de Arte, 35, pp. 63-82.

Álvarez Luna, María de los Ángeles/Guerrero Vega, José María/Romero Bejarano, Manuel (2003): La intervención en el patrimonio. El caso de las iglesias jerezanas (1850-2000). Jerez de la Frontera: Ayuntamiento de Jerez.

Antón Portillo, Jesús/Jácome González, José (2001): “Apuntes histórico-artísticos de Jerez de la Frontera en los siglos XVI-XVIII ( $2^{\mathrm{a}}$ serie)”. En: Revista de Historia de Jerez, 7, pp. 103-123.

Aroca Vicenti, Fernando (2002): Arquitectura y urbanismo en el Jerez del siglo $X$ VIII. Jerez de la Frontera: CUES.

(2005): "Arquitectura civil jerezana del siglo XVIII. Revisión y nuevos datos". En: Laboratorio de Arte, 18, pp. 327-347.

Borromeo, Carlo ([1577] 1859): Instructionum fabricae ecclesiasticae et supellectilis ecclesiasticae. Tarragona: Francisco Arís.

\footnotetext{
${ }^{50}$ Álvarez Luna/Guerrero Vega/Romero Bejarano, 2003: 106-111 y 250-254.
}

${ }^{51}$ Los distintos avatares históricos padecidos a partir del siglo XIX por las comunidades de regulares -especialmente las exclaustraciones- y las caprichosas reformas llevadas a cabo en muchos presbiterios tras la revolución litúrgica posterior al último concilio ecuménico han provocado que no se conserven los púlpitos litúrgicos de ninguno de estos templos jerezanos.

52 Pomar Rodil, 2016: 97-103. 
Cabrol, Fernand/Leclercq, Henri (1907-1953): Dictionnaire d'archéologie chrétienne et de liturgie. París: Letouzey \& Ané.

Caremoniale Episcoporum iussu Clementis VIII pontificis maximino vissimereformatum ómnibus ecclesiis, prccipueautem Metropolitanis, Cathedralibus et Collegiatis per utile ac necessarium (1600). Venecia: Nicolai Masserini.

Carrero Santamaría, Eduardo (2008): "Centro y periferia en la ordenación de espacios litúrgicos: las estructuras corales”. En: Hortus Artium Mediaevalium, 14, pp. 159-179.

De los Ríos Martínez, Esperanza (1996): "Las intervenciones de Alonso Cano y Francisco Gálvez en los púlpitos de la parroquia de Santiago y San Miguel de Jerez de la Frontera". En: Laboratorio de Arte, 9, pp. 143-156.

Gallego de Miguel, Amelia (1981): "Rejería castellana en la catedral de Sevilla: las rejas de la capilla mayor, coro y los púlpitos". En: Boletín de Bellas Artes, 9, pp. 219-245.

Gascón, Juan (1585): Instruction para dezir missa conforme al missal romano sacada en estylo claro del mismo missal. Huesca: Juan Pérez de Valdivielso.

Heid, Stefan (2017): "Funktion und Ausrichtung des Ambo in der byzantinischen und römischen Tradition". En: Römische Quartalschrift für Christliche Altertumskunde und Kirchengeschichte, 112, pp. 76-102.

Herz, Alexandra (1988): "Cardinal Cesare Baronio's Restoration of SS. Nereo ed Achileo and S. Cesareo de 'Appia". En: The Art Bulletin, 70, pp. 590-620.

Jiménez López de Eguileta, Javier E./Pomar Rodil, Pablo J. (2014): "La colegiata medieval de San Salvador de Jerez de la Frontera". En: 750 aniversario de la incorporación de Jerez a la Corona de Castilla: 1264-2014. Jerez de la Frontera: Ayuntamiento de Jerez, pp. 459-484.

Jiménez Martín, Alfonso (2006): "Las fechas de las formas. Selección crítica de fuentes documentales para la cronología del edificio medieval". En: La catedral gótica de Sevilla. Fundación y fábrica de la obra nueva. Sevilla: Universidad de Sevilla, pp. 15-114.

Jungmann, Josef Andreas (1951): El sacrificio de la misa. Tratado histórico litúrgico. Madrid: BAC.

Lang, Uwe Michael (2007): Volverse hacia el Señor. Orientación en la plegaria litúrgica. Madrid: Ediciones Cristiandad.

Lavin, Irving (1959): "The Sources of Donatello's Pulpits in San Lorenzo: Revival and Freedom of Choice in the Early Renaissance". En: The Art Bulletin, 41, pp. 19-38.

(1994): "I pulpiti di Donatello in San Lorenzo e il revival paleocristiano". En: Passato e presente nella storia dell'arte. Turín: Einaudi, pp. 3-43.

Mariscal Rodríguez, Miguel Á./Pomar Rodil, Pablo J. (2001): "Historicismos en las iglesias de Jerez de la Frontera. Los altares-templete". En: Revista de Historia de Jerez, 7, pp. 93-102. 
Milone, Antonio/Novello, Roberto Paolo (2006): "Il corpus itálico degli amboni medievali". En: Goffredo Boselli (coord.): L'Ambone. Tavola della parola di Dio. Magnano: Edizioni Qiqajon, pp. 101-131.

Pescador y Gutiérrez del Valle, Mariano (1914): Guía artística de Xerez de la Frontera, o sea, sucinta descripción de sus principales monumentos. Sanlúcar de Barrameda: Ardibio Pulet.

Pomar Rodil, Pablo J. (2002): "La reforma de los ambones y el púlpito de la parroquia de Santiago de Sevilla en 1611". En: Laboratorio de Arte, 15, pp. 365-371.

- (2015): "La ubicación del coro en las iglesias de España. San Pío V, Felipe II y el breve Ad hoc nos Deus unxit". En: Choir Stalls in Architecture and Architecture in Choirs Stalls. Cambridge: Cambridge Scholars Publishing, pp. 87-97. (2016): "Los feligreses y el templo. Espacio arquitectónico, liturgia y cura de almas". En: Pérez Mulet, Fernando (coord.): Nuevas aportaciones a la Historia del Arte en Jerez de la Frontera y su entorno. Cádiz: Universidad de Cádiz, pp. 79-104.

Rallón, Fray Esteban ([c. 1665] 2003): Historia de la ciudad de Xerez de la Frontera y de los reyes que la dominaron desde su primera fundación. Jerez de la Frontera: Universidad de Cádiz, t. IV.

Repetto Betes, José Luis (1978): La obra del templo de la Colegial de Jerez de la Frontera. Cádiz: Diputación Provincial de Cádiz.

Righetti, Mario (1956): Historia de la liturgia. Madrid: BAC.

Rodríguez Estévez, Juan Clemente (2006): "Los constructores de la Catedral". En: La catedral gótica de Sevilla. Fundación y fábrica de la obra nueva. Sevi1la: Universidad de Sevilla, pp. 147-208

Romero Bejarano, Manuel (2014): Maestros de obras de ascendencia portuguesa en el tardogótico de la baja Andalucía. Tesis doctoral. Sevilla: Universidad de Sevilla. https://idus.us.es/handle/11441/69330.

Romero Bejarano, Manuel/Romero Medina, Raúl (2011): "Pedro Fernández de la Zarza: un maestro tardogótico de la Baja Andalucía (1494-1569)". En: Alonso Ruiz, Begoña (coord.): La arquitectura tardogótica castellana entre Europa y América. Madrid: Sílex, 2011, pp. 197-212.

Ruiz Alcoholado, Pedro (1589): Ceremonial romano para missas cantadas y rezadas en el qual se ponen todas las rúbricas generales y particulares del Missal Romano, que divulgó el Papa Pio V con aduertencias y resoluciones de muchas dudas y al cabo se trata de lo tocante a los ministros y altar todo nueuamente ordenado, facilitado y reuisto. Alcalá de Henares: Herederos de Juan Gracián.

Sancho de Sopranis, Hipólito (1936): "Papeletas para una serie de artistas regionales (segunda serie)". En: Guión, 27, pp. 5-6.

Stabenow, Jörg (2006): "Il duplice pulpito di Carlo Borromeo nel Duomo di Milano: tradizione e invenzione". En: Stabenow, Jörg (coord.): Lo spazio e il culto. Relazioni tra edificio ecclesiale e uso liturgico dal XV al XVI secolo. Venecia: Marsilio, pp. 227-280. 


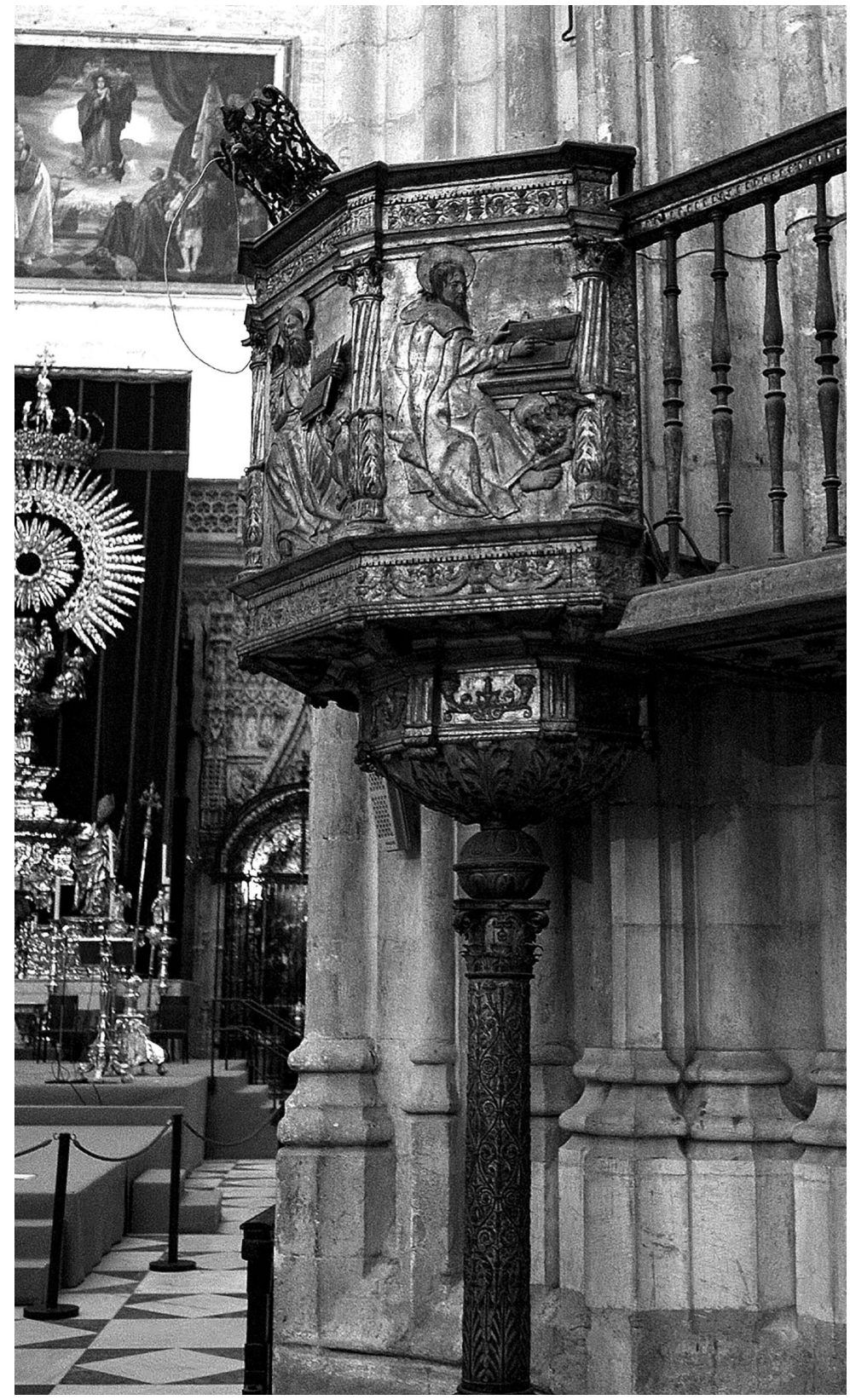

Figura 1. Francisco de Salamanca, Púlpito del evangelio, 1527-1532, catedral de Sevilla. Foto: Pablo J. Pomar Rodil. 


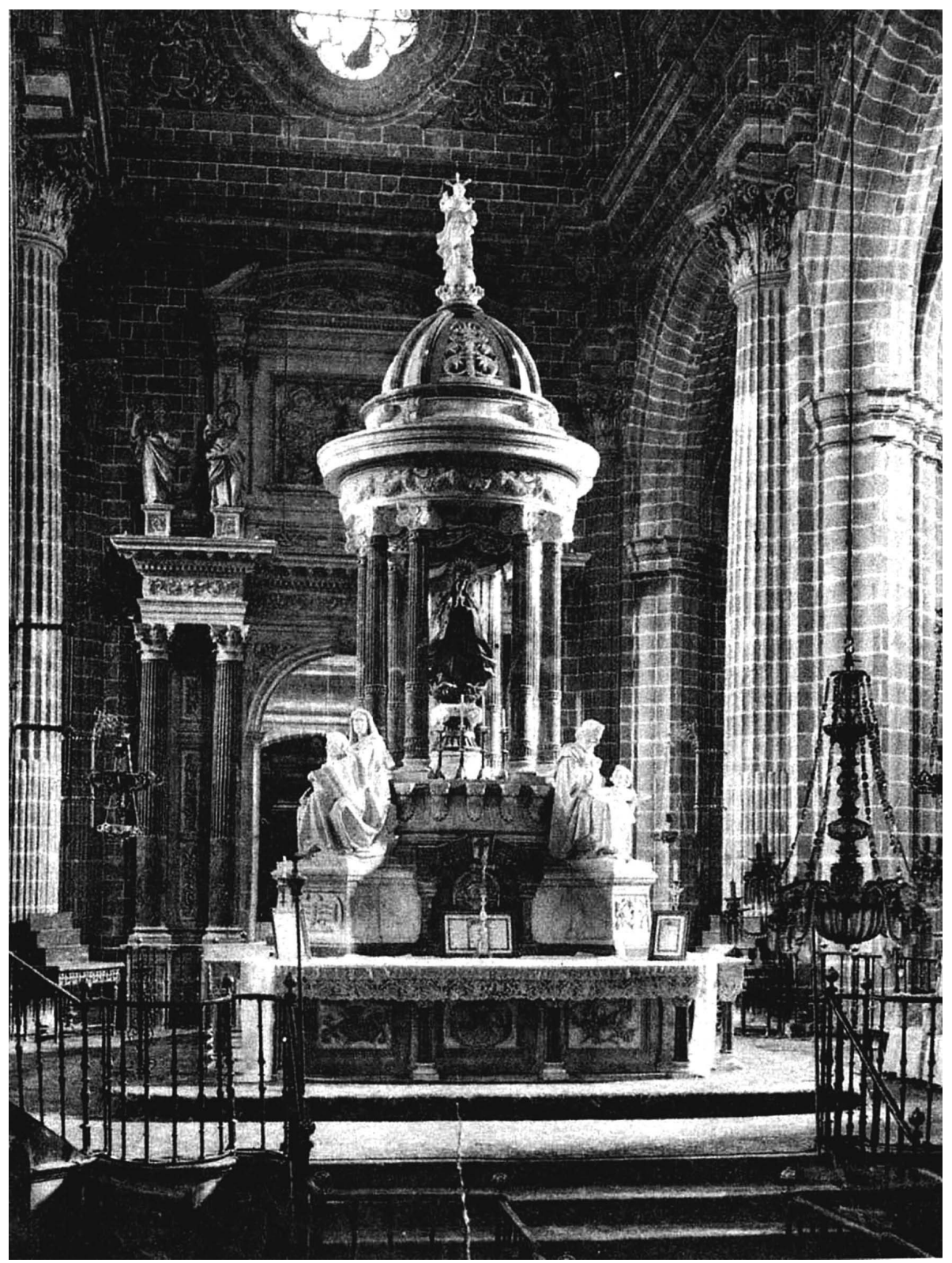

Figura 2. Pedro Dorado, Púlpitos de baranda, 1778, colegiata de Jerez de la Frontera. 


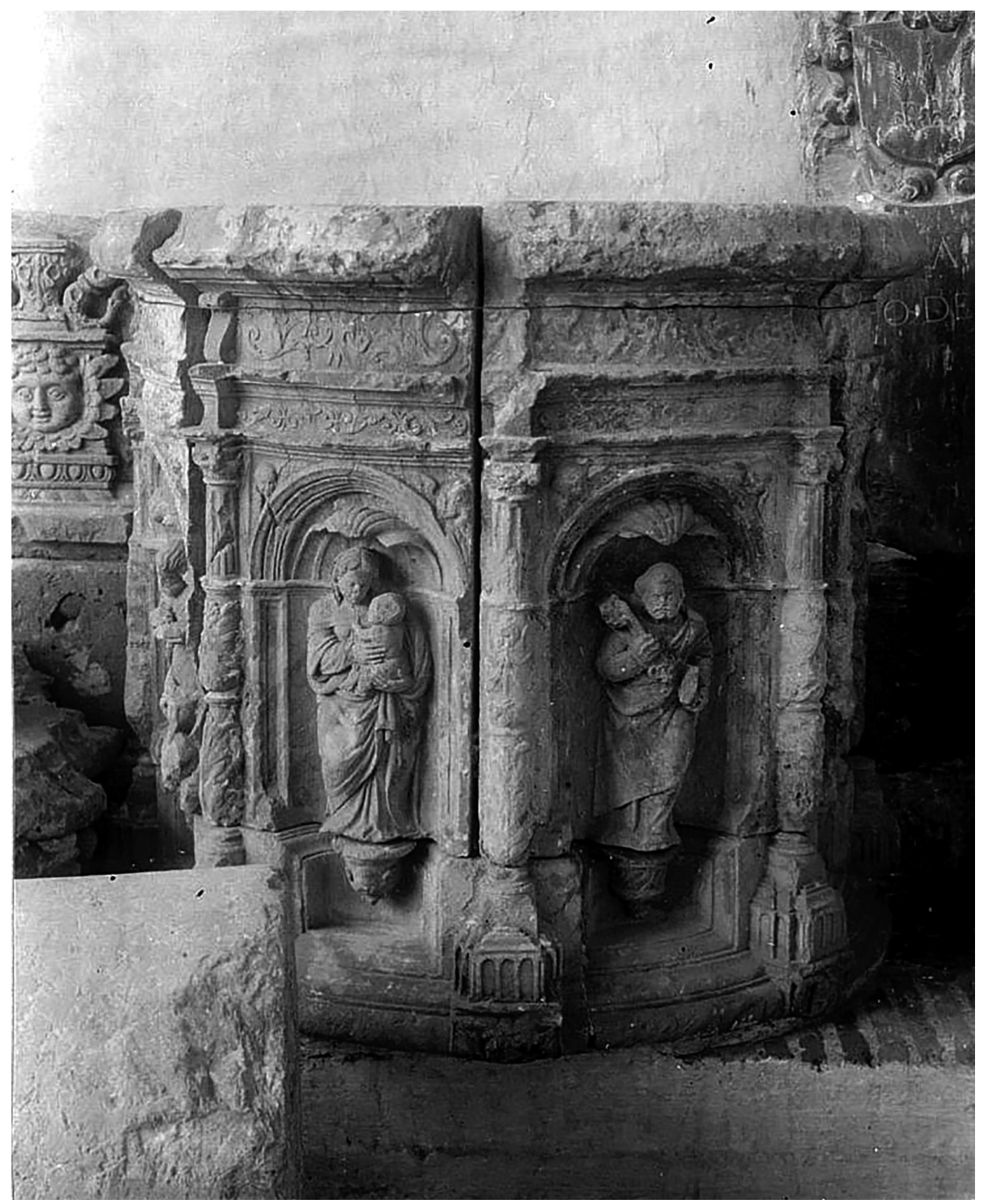

Figura 3. ¿Cristóbal de Voisín?, Púlpito de la parroquia de San Miguel, hacia 1550, Museo Arqueológico de Jerez de la Frontera. Foto: Catálogo Monumental de España. 


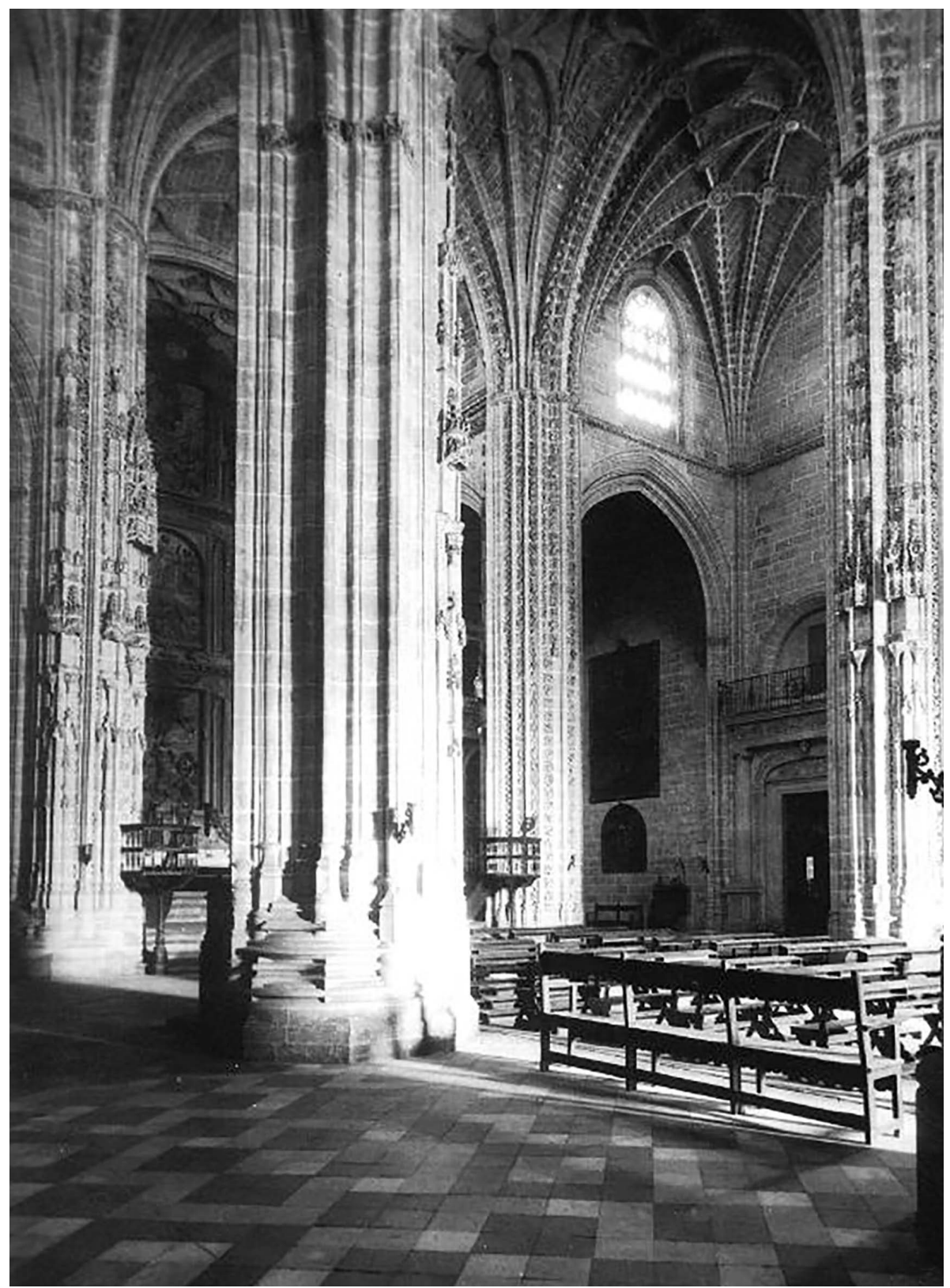

Figura 4. Pedro Dorado (atribución), Púlpitos, hacia 1789, parroquia de San Miguel, Jerez de la Frontera. Foto: Archivo Mas. 


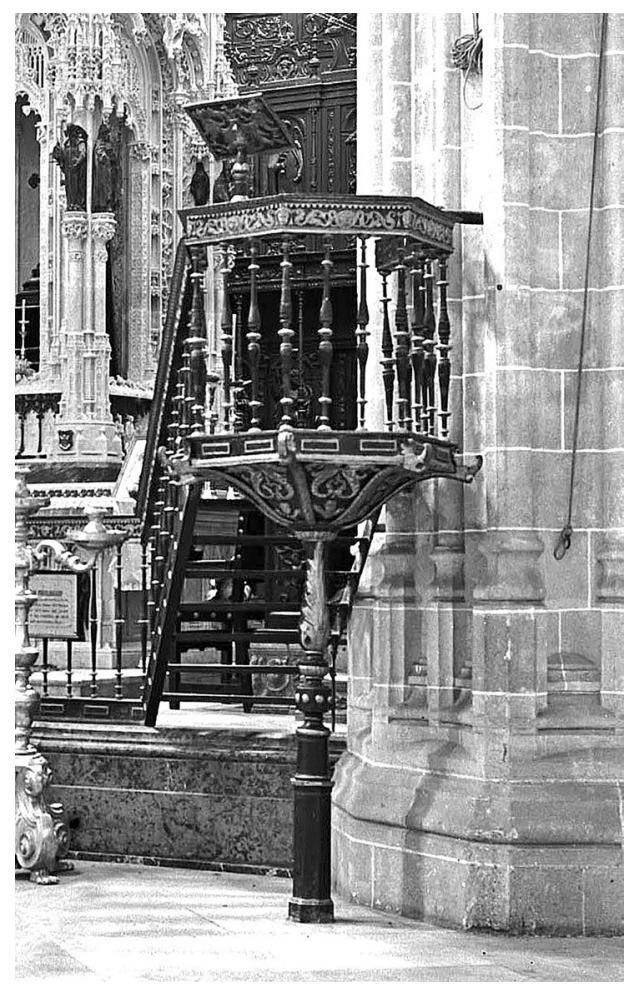

Figura 5. Roque y Francisco de Caos, Púlpito de la epístola, 1628, parroquia de Santiago, Jerez de la Frontera.

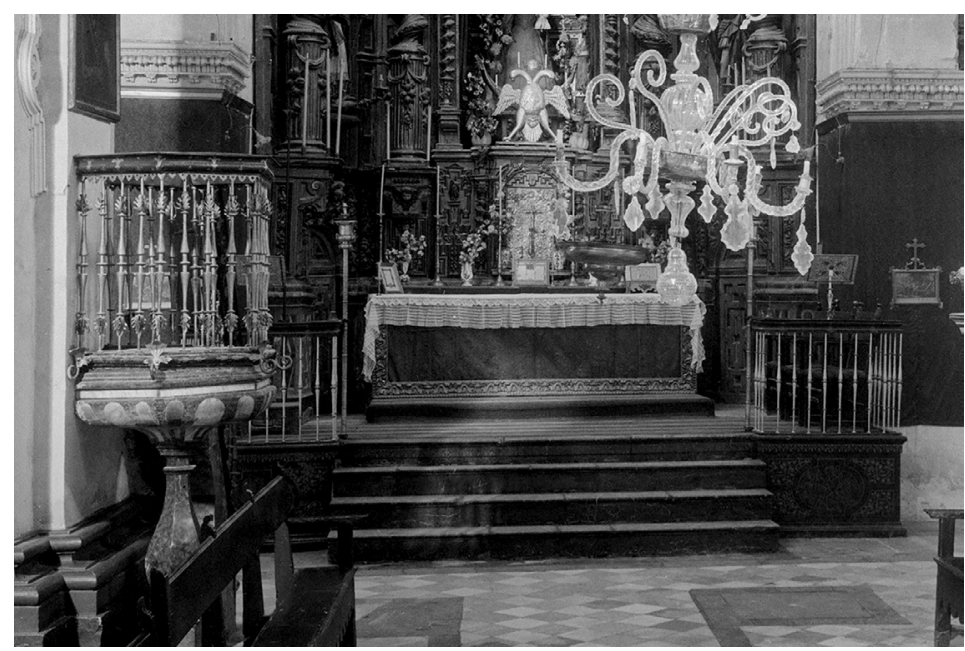

Figura 6. Púlpitos, 1729, parroquia de San Lucas, Jerez de la Frontera. Foto: Archivo Mas. 